\title{
1 Consequences of tropical forest conversion to oil palm on soil bacterial community
}

\section{2 and network structure}

4 Stephen A. Wood ${ }^{1,2^{*}}$, Jack A. Gilbert ${ }^{3,4}$, Jonathan W. Leff ${ }^{5}$, Noah Fierer ${ }^{5}$, Heather

5 D’Angelo $^{6}$, Carling Bateman ${ }^{7}$, Seren M. Gedallovich ${ }^{7}$, Caitlyn M. Gillikin ${ }^{7}$, Mary R.

6 Gradoville $^{8}$, Patahayah Mansor ${ }^{9}$, Audrey Massmann ${ }^{7}$, Nina Yang ${ }^{7}$, Benjamin L. Turner ${ }^{10}$,

$7 \quad$ Francis Q. Brearley ${ }^{11}$, Krista L. McGuire ${ }^{6,7}$

8

$9{ }^{1}$ Yale School of Forestry \& Environmental Studies, New Haven, CT USA 06511

$10 \quad 2$ The Nature Conservancy, Arlington, VA USA 22203

$11{ }^{3}$ The Microbiome Center, Argonne National Laboratory, Lemont, IL USA 60439

$12{ }^{4}$ Department of Surgery, University of Chicago, Chicago, IL USA 60637

$13{ }^{5}$ Department of Ecology and Evolutionary Biology, University of Colorado, Boulder, CO

$14 \quad$ USA 80302

$15{ }^{6}$ Department of Ecology, Evolution \& Environmental Biology, Columbia University,

16 New York, NY USA 10027

$17{ }^{7}$ Department of Biology, Barnard College of Columbia University, New York, NY USA

$18 \quad 10027$

$19{ }^{8}$ College of Earth, Ocean, and Atmospheric Sciences, Oregon State University, Corvallis,

20 OR USA 97331

$21{ }^{9}$ Forest Research Institute Malaysia, 52109 Kepong, Selangor, Malaysia

$22{ }^{10}$ Smithsonian Tropical Research Institute, Apartado 0843-03092, Balboa, Ancon,

23 Republic of Panama 
$24{ }^{11}$ School of Science and the Environment, Manchester Metropolitan University,

25 Manchester, UK

$26 *$ Corresponding author: stephenawood@gmail.com; 370 Prospect St., New Haven, CT,

$27 \quad 06511$

29 Abstract

30 Tropical forest conversion to agriculture is a major global change process. Understanding

31 of the ecological consequences of this conversion are limited by poor knowledge of how

32 soil microorganisms respond. We analyzed the response of soil bacteria to conversion

33 from primary rain forest to oil palm plantation and regenerating logged forest in

34 Malaysia. Bacterial diversity increased by approximately $20 \%$ with conversion to oil

35 palm because of higher $\mathrm{pH}$ due to liming by plantation managers. Phylogenetic clustering

36 indicated that bacterial communities were determined by environmental filtering.

37 Regenerating logged forests did not have significantly different soil chemistry, which did

38 not correspond with significant differences in bacterial richness, diversity, or the relative

39 abundances of particular taxa. However, there were significant differences in the

40 structure of bacterial community networks between regenerating logged forests and

41 primary forests, highlighting previously unobserved effects of these two land uses.

42 Network analysis highlighted taxa that are potentially central to bacterial networks, but

43 have low relative abundances, suggesting that these rare taxa could play an ecological

44 role and therefore warrant further research.

45 
46 Keywords: bacteria; microbial diversity; microbial networks; oil palm; rare microbes;

47 tropical deforestation 


\section{Introduction}

Tropical forests have long been under threat of conversion to other land uses - more than

50 half of the original extent of rain forests has been converted (Asner et al., 2009). Since tropical

51 forests are home to more than two-thirds of all terrestrial plant and animal species (Brooks et al.,

52 2002; Dirzo and Raven, 2003; Gardner et al., 2009), this loss of tropical forest comes hand-in-

53 hand with a loss in biodiversity. Yet this story of conversion and species loss may or may not

54 translate to loss of the huge diversity of soil organisms found under foot.

55 Soil microorganisms, which make up the bulk of soil diversity, are widely recognized to

56 be essential to the functioning of terrestrial ecosystems. Microbial activity is responsible for

57 many biogeochemical redox reactions (Falkowski et al., 2008). Both negative and positive

58 feedbacks between soil organisms and plant communities contribute to ecological structure and

59 functioning in the tropics (Bagchi et al., 2010; Kiers et al., 2000; Mangan et al., 2010). Given the

60 importance of soil microorganisms to biogeochemical cycling and plant-soil feedbacks,

61 understanding if soil microbes are threatened by large-scale tropical land-use change is necessary

62 to understand and predict broader functional consequences of land-use change.

63 An growing body of work has documented how soil microbial communities respond to

64 human-induced environmental change (Thomas W Crowther et al., 2014; da C Jesus et al., 2009;

65 de Carvalho et al., 2016; Fierer et al., 2012; Lee-Cruz et al., 2013; Leff et al., 2015; McGuire et

66 al., 2015; Ramirez et al., 2012, 2010; Rodrigues et al., 2013; Tripathi et al., 2016; Wood et al.,

67 2015). Several consistent patterns have emerged from this work. Changes in the bacterial

68 community are largely governed by changes in soil chemical properties, mainly pH (Lauber et

69 al., 2009; Rousk et al., 2010). Bacterial diversity decreases sharply with decreases in pH, partly

70 due to an associated increase in the relative abundance of taxa such as Acidobacteria. By 
71 contrast, fungi are less sensitive to changes in $\mathrm{pH}$. Instead, the dominant control on fungi tends to

72 be a combination of factors such as soil carbon, local soil moisture, and plant composition

73 (Barberán et al., 2015; Fierer et al., 2003; Prescott and Grayston, 2013; Prober et al., 2015;

74 Toberman et al., 2008). The response of soil microbial communities to land-use change is in part

75 determined by the properties of the underlying soil, with the greatest difference between forest

76 communities and grassland communities occurring on sandier soils (Thomas W Crowther et al.,

77 2014). This constraint of soil type may be due to lower moisture and carbon holding capacity in

78 sandier soils or inability of sandier soil to buffer against changes in $\mathrm{pH}$, which are dominant

79 controls of fungal and bacterial communities, respectively.

80 These now robust patterns rely on inference generated from the relative abundance of soil

81 microbes, whether directly or through abundance-weighted diversity metrics. Most microbial

82 taxa are, however, rare (Locey and Lennon, 2016) - i.e. low in relative abundance - and these

83 abundance-weighted metrics may miss possible contributions of rare species. In plant

84 communities, rare species can make important contributions to ecosystem structure and function

85 (Jain et al., 2014; Lyons and Schwartz, 2001). Whether the same is true for microbes remains

86 less well known, but evidence is mounting that loss of rare microbial taxa can play an important

87 role in community structure (Shade et al., 2014) and ecosystem functioning, especially through

88 modifying plant-soil feedbacks (Hol et al., 2015, 2010). Rare taxa, by virtue of being rare, may

89 exhibit different life history strategies than abundant taxa (Murray et al., 2002) and therefore

90 respond differently to land-use change. If this is the case, then understanding their responses may

91 highlight different trends in the response of microbial communities to land-use change. Network

92 analysis, which has been widely used to study the impacts of global change on plant and animal

93 diversity (Ings et al., 2009), may help inform understanding of the ecological role of rare bacteria 
94 by highlighting how rare taxa co-occur with well-studied taxa, which could indicate similar

95 ecological roles between rare and well-studied taxa (Ma et al., 2016).

96 Based on the literature cited above showing that bacterial communities are strongly

97 structured by abiotic conditions, we expected that bacterial community composition and diversity

98 would follow land-use changes that modified soil chemical properties, particularly $\mathrm{pH}$. Because

99 McGuire et al (2015) found elevated $\mathrm{pH}$ under oil palm—but no differences between

100 regenerating and primary forests - we expected that bacterial diversity and community

101 composition would differ between oil palm and the native forest types, but not among the native

102 forest types. For network composition, a chronosequence of abandoned agricultural land showed

103 that fungal networks became more connected in older sites with a shift towards more fungal-

104 dominated food webs (Morriën et al., 2017). Based on this we developed two competing

105 hypotheses: (H1) bacterial network structure follows patterns observed in fungi and becomes

106 more interconnected moving from disturbed to primary vegetation; (H2) because food webs shift

107 to fungal dominance under primary vegetation, bacterial networks decrease in complexity as

108 fungal communities increase in complexity.

109 To evaluate our expectations and the consequences of forest conversion on soil microbial

110 composition, we compared bacterial communities from three sites in Malaysia: a primary

111 lowland mixed dipterocarp forest, a regenerating dipterocarp forest that had been selectively

112 logged 50 years ago, and a 25-year old oil palm plantation. Over the past few decades, palm oil,

113 the commercial commodity extracted from the oil palm plant (Elaeis guineensis; Arecaceae) has

114 been the most rapidly growing crop in the tropics. Indonesia and Malaysia alone account for

115 more than $80 \%$ of all palm oil production and not coincidentally, this region of the world also

116 experiences the highest proportional rate of deforestation (Carlson et al., 2012; Hansen et al., 
117 2013). Thus, oil palm plantations are highly relevant for evaluating the consequences of large-

118 scale tropical deforestation on soil microbial communities.

120 2. Material and methods

1212.1 Site description and field sampling

122 Soil samples were collected from lowland sites in peninsular Malaysia in the state of

123 Negeri Sembilan, as previously described (McGuire et al., 2015). Briefly, we sampled from three

124 land-use types: primary rain forest (primary forest), forest regenerating from logging 50 years

125 prior (regenerating forest) and an oil palm plantation in active cultivation for 25 years (oil palm).

126 The regenerating and primary forests area are located in the Pasoh Forest Reserve $\left(2^{\circ} 5^{\prime} \mathrm{N}\right.$,

$127102^{\circ} 18^{\prime} \mathrm{W}, 80 \mathrm{~m}$ asl), with the Dipterocarpaceae family comprising nearly one-third of the basal

128 area of canopy trees (Manokaran et al., 2004). The oil palm plantation was located less than 500

$129 \mathrm{~m}$ from the Pasoh Forest Reserve. Climate in this region is aseasonal with mean annual

130 precipitation of $1,788 \mathrm{~mm}$ and average minimum and maximum temperatures of 22.7 and $33.2 \mathrm{C}$,

131 respectively. The dominant soil type in the lowland forest plots sampled is Ultisols (Adzmi et al., 132 2010).

133 Within each land-use type (primary forest, regenerating forest, and oil palm plantation),

134 three replicate plots $(20 \times 20 \mathrm{~m})$ were established and five soil samples were collected from each

135 plot during a single sampling event. All sampling plots were at least $1 \mathrm{~km}$ away from each other,

136 but selected on the same underlying soil type and slope position. The collected samples were

137 divided into three sampling depths: $0-2 \mathrm{~cm}, 2-10 \mathrm{~cm}$, and 10-20 cm. All plots were separated by

138 at least $500 \mathrm{~m}$. Sample replicates were composited by depth to one sample per depth, per plot

139 and were placed in sterile plastic bags, sealed and frozen at $-20{ }^{\circ} \mathrm{C}$ on the day of collection. In the 
140 laboratory, all soil samples were passed through a $2 \mathrm{~mm}$ sieve, homogenized, and stored frozen

141 at $-20^{\circ} \mathrm{C}$ until laboratory analyses were performed.

$143 \quad 2.2$ Laboratory analyses

144 We amplified and sequenced a portion of the 16S rRNA gene to assess bacterial

145 communities in a similar manner as described previously (Caporaso et al., 2012). Amplifications

146 were performed on DNA isolates from the MoBio PowerSoil extraction kit (MoBio, Carlsbad,

147 CA), which were the isolates used for prior analysis of soil fungi (McGuire et al., 2015). PCR

148 amplification was performed with the primers $515 \mathrm{f}$ and $806 \mathrm{r}$, which included sequencing

149 adapters for the Illumina sequencing platform, and the reverse primer contained a 12-bp barcode

150 unique to each sample. Amplicons combined and sequenced on an Illumina MiSeq instrument

151 using a paired-end 151-bp sequencing kit. Raw amplicon sequences were demultiplexed and

152 processed with the UPARSE pipeline (Edgar, 2013) as in Ramirez et al (Ramirez et al., 2014).

153 Paired end sequence reads were merged prior to additional processing. Sequences were quality

154 filtered using a "maxee" value of 0.5 and singletons were removed. Sequences were clustered

155 into operational taxonomic units at a threshold of $\geq 97 \%$ sequence similarity. Merged,

156 demultiplexed sequences were mapped against our de novo database of clustered OTUs to get

157 counts of sequences per OUT and sample. Taxonomy was assigned to OTUs using the RDP

158 classifier (Wang et al., 2007) with a confidence threshold of 0.5 and trained on the Greengenes

159 database (McDonald et al., 2012). Samples were rarefied to 7,000 sequences per sample prior to

160 downstream analysis. Previous analyses focused on analysis of fungal community dynamics

161 contain data on microbial biomass, enzymatic activity, fungal diversity, fungal composition, and

162 soil physical and chemical properties (D’Angelo et al., 2015; McGuire et al., 2015). 


\section{$164 \quad 2.3$ Analytic methods}

$165 \quad$ 2.3.1 Diversity

166 We calculated several common ecological diversity metrics including species richness,

167 evenness, Shannon, and Faith's Phylogenetic Diversity (PD). Shannon is a diversity metric

168 where the relative abundance of species is weighted by evenness. Faith's PD sums the branch

169 lengths of a phylogeny for a given site and uses the resulting branch length sum as a metric of

170 phylogenetic diversity. Diversity metrics were calculated for each site using the vegan package

171 (Oksanen et al., 2016) of R (Core, 2016), except for phylogenetic diversity, which was calculated

172 in the picante package (Kembel et al., 2010).

173

$174 \quad$ 2.3.2 Phylogenetic analysis

175 Assessing the extent of phylogenetic clustering in a community can be used to infer the

176 degree to which communities are likely structured by environmental filtering or competition

177 (Cavender-Bares et al., 2009; Webb and Ackerly, 2002). Using this approach, the observed

178 phylogenetic distribution of a community is compared to a null model or randomization

179 procedure to determine whether the observed phylogeny is more or less clustered than would be

180 expected at random. Clustering suggests environmental factors structure community assembly,

181 whereas overdispersion suggests that biological interactions, such as competition, are the

182 dominant force in community assembly. To apply this approach, we used a phylogeny generated

183 from sequence OTUs to create a community dissimilarity matrix in the picante package in $\mathrm{R}$

184 (Kembel et al., 2010). We then calculated a relative abundance-weighted standardized effect size

185 for mean pairwise distance (MPD) and mean nearest neighbor distance (MNTD), which are 
186 metrics of mean pairwise phylogenetic distance within the community (Webb et al., 2008). MPD

187 calculates mean pairwise distance between all OTUs in each site. MNTD calculates the average

188 distance separating each OTU in a site from its nearest phylogenetic relative. The standardized

189 effect size of these metrics compares the observed phylogenetic distribution to an expected

190 distribution under some null model or randomized scenario. To ensure robustness of our

191 approach, we calculated MPD and MNTD using two null model scenarios, one that randomizes

192 the tips of the phylogeny (Tip Randomization) and a second that randomizes that community

193 abundances within samples, but holds richness constant (Richness Randomization).

195 2.3.3. Network analysis

196 To analyze network structure, we used data on the relative abundances of bacterial taxa

197 by land-use types to create a taxonomic association network. This procedure suggests an

198 association network by comparing observed taxonomic co-occurrences with a set of predicted

199 co-occurrences from null models with the same richness and relative abundances as the observed

200 community. Standardized effect-size scores are calculated for the observed vs. predicted data,

201 significant associations are retained, and scores are converted to an association network. We

202 generated association networks using the netassoc package (Blonder and Morueta-Holme, 2015).

203 We calculated a number of statistics to characterize the nature of networks under the

204 three land-use categories. Modularity measures the compartmentalization of a network into sub-

205 networks, or modules (Newman, 2006). High modularity scores indicate the presence of many

206 connections among vertices within a module, but few connections to vertices of different

207 modules. We calculated modularity using the modularity function in the igraph package (Csardi

208 and Nepusz, 2006). Assortativity measures the tendency for similar vertices to be linked with 
each other (Newman, 2002). We calculated assortativity using the assortativity_degree function

210 in the igraph package. Transitivity represents the likelihood that neighboring vertices are linked,

211 and then linked to other adjacent vertices à la transitivity property (Barrat et al., 2004). We

212 calculated transitivity using the transitivity function in the igraph package. We also determine,

213 for each land-use category, which taxa (vertices) had the highest number of paths connected to

214 other vertices. This is also known as betweenness or network centrality (Freeman, 1978). We

215 calculated this using the vertex_connectivity function in the igraph package.

216 To determine whether network statistics were significantly different among the three

217 land-use categories, we generated 10,000 random networks with similar sizes and calculated the

218 mean and standard deviation of the same statistics. We then calculated a $\mathrm{z}$-score for each of the

219 observed networks to determine how many standard deviations it fell away from the expected

220 value given from the network randomization procedure. The randomly generated network was a

221 regional network that had the same number of vertices and edges as the observed network that

222 includes all sites, regardless of land-use category. Comparing to this regional network therefore

223 highlights how environmental changes would affect the locally observed network.

225 2.3.4 Statistical analyses

226 We determined bacterial community similarity among land-use types and soil horizons

227 using ANOSIM; non-metric multi-dimensional scaling (NMDS) was used to visualize clusters.

228 We used linear models to determine the impact of land-use type on bacterial diversity. We first

229 tested response variables for normality using the Shapiro-Wilk test. In cases of non-normality,

230 response variables were transformed using a Box-Cox transformation. All differences were 
231 considered significant at a 0.05 threshold and marginally significant at a 0.10 threshold (Hurlbert

232 and Lombardi, 2009).

\section{3. Results}

The soil bacterial community did not differ by sampling depth (ANOSIM $\mathrm{R}=-0.05, \mathrm{P}=$

236 0.77). We therefore pooled samples across depths to increase sample size and statistical power.

237 Because samples collected from the same site at different depths are not independent, we

238 controlled for non-independence by clustering standard errors of all samples from the same site.

239 We observed a significant difference in the soil bacterial community among land-use types

240 (ANOSIM R $=0.59, \mathrm{P}<0.01$ ). Specifically, oil palm soil bacterial communities clustered

241 independently of regenerating and primary forest (Figure 1; Stress $=0.06$ ). There was strong

242 evidence that bacterial communities from all land-use types were phylogenetically clustered (as

243 opposed to overdispersed) relative to a null model (MPD \& MNTD $<0 ; \mathrm{P}=0.01$; Table 1).

244 There was no evidence for significant differences in the degree of phylogenetic clustering among

245 land-use types.

246

247 3.1 Diversity

248 To explore the nature of the difference between bacterial communities, we assessed

249 potential differences in several ecological diversity metrics. We observed significantly elevated

250 diversity of soil bacteria in oil palm compared to regenerating and primary forests (Table 2). For

251 instance, Shannon diversity of soil bacteria increased by approximately $20 \%$ under oil palm,

252 compared to primary and regenerating forests $(\mathrm{p}<0.001)$. This general pattern was robust to all

253 diversity indices used, including species richness $(\mathrm{p}<0.001)$, evenness $(\mathrm{p}=0.001)$, and Faith's 
254 phylogenetic diversity $(\mathrm{p}<0.001)$. Statistical models that included only land-use type as

255 predictor variables, explained between $50 \%$ and $77 \%$ of the variation in diversity metrics (Table

256 2).

\subsection{Community Composition}

259 We observed significant changes in the relative abundances of several key taxa among

260 land-use types (Figure 2; $\mathrm{p}<0.05$ for all groups shown). The most significant changes were

261 between oil palm and the two forest types, with little difference between regenerating and

262 primary forests. Most taxa increased in relative abundance under oil palm, compared to

263 regenerating and primary forest (Figure 2). A notable exception was Acidobacteria, which was

264 the only taxonomic group to significantly decrease in relative abundance (by approximately

$26540 \%$ ) under oil palm compared to regenerating and primary forest.

\subsection{Network Structure}

268 Networks of soil bacterial communities were more modular under oil palm and logging

269 than was expected at random, given the taxa present in the regional species pool (Figure 3; Table

$2703 a, b)$. Regenerating forests were around eight times more modular, and oil palm plantations

271 approximately five times more modular, than primary forests, but oil palm was only 0.4 times

272 less modular than regenerating forests. Similar taxa were 2.5 times less likely to be associated

273 with each other under oil palm compared to primary forests, whereas similar taxa were three

274 times more likely to be associated in regenerating forest soil compared to primary forest (Figure

2753 ; Table 3a, b). All land-use types had similar values of transitivity - the likelihood that

276 neighboring vertices are linked — but were all less than expected by random (Table $3 a, b)$. 
For all taxa, we calculated the number of edges connecting to other vertices, for each

278 land-use type. We found that several taxa played central roles (high degree of connectivity) in

279 certain land-use networks, but were not present or were unimportant in others (Figure 3; Table

280 4). For instance, Acidobacteria had 244 connections under oil palm, but not under regenerating

281 or primary forest. Actinobacteria had 250 connections under primary forest, but none under

282 regenerating forest and oil palm. NKB19 was not present under oil palm and regenerating forest,

283 but had the most connections under primary forest. Planctomycetes and Gemmatimonadetes were

284 two of the most central taxa under regenerating forest soils, but neither had connections in either

285 oil palm or primary forest. Some taxa were central across all land-use types, such as GNO2 and

286 Nitrospirae.

287 The regenerating forest network had the fewest number of taxa co-occurring, but most 288 relationships were high in magnitude - whether positive or negative (Figure 4). Oil palm had the

289 most co-occurrence relationships, but was dominated by a few strong positive interactions

290 (Figure 4). Primary forest had a mix of positive and negative interactions, both weak and strong

291 (Figure 4). The correlation between the relative abundances of two taxa was a significant

292 predictor of the co-occurrence strength between those two taxa $(\mathrm{P}<0.00)$, but explained only

$29319 \%$ of the variance in co-occurrence scores.

295 4. Discussion

2964.1 Effects of oil palm on the soil bacterial community

297 We expected that bacterial diversity would be greatest under oil palm because of greater

$298 \mathrm{pH}$. We found support for this hypothesis, which conforms with other work in tropical forests

299 that find increases in measures of bacterial diversity after conversion of tropical forest ( $\mathrm{da} C$ 
300 Jesus et al., 2009; de Carvalho et al., 2016; Lee-Cruz et al., 2013; Rodrigues et al., 2013; Tripathi

301 et al., 2016). Increases in bacterial diversity were associated with significant increases in

302 evenness, suggesting a disrupted microbial community. In our study, conversion of primary

303 forest to oil palm plantation was associated with an increase in $\mathrm{pH}-$ from $4.7 \pm 0.1$ to

$3045.1 \pm 0.1$ (Brearley, 2015; McGuire et al., 2015). Higher $\mathrm{pH}$ is often associated with greater soil

305 bacterial diversity, with the slope of this relationship greatest in low $\mathrm{pH}$ conditions (Lauber et al.,

306 2009). Because of highly acidic tropical forest soils, oil palm plantation managers lime soils for

307 improved production (Tripathi et al., 2012). Since $\mathrm{pH}$ is the dominant driver of soil bacterial

308 communities across biomes (Lauber et al., 2009; Rousk et al., 2010; Tripathi et al., 2013, 2012),

309 an increase in bacterial diversity accompanying liming conforms with expectations from the

310 literature. Our observed decrease in the relative abundance of Acidobacteria - which tend to have

311 higher relative abundances with low $\mathrm{pH}$ - in oil palm soils also supports our conclusion that

312 changes in the bacterial community under oil palm cultivation were largely due to changes in $\mathrm{pH}$.

313 This claim is furthermore supported by our finding that the bacterial community is highly

314 phylogenetically clustered, which is often used to infer that environmental filtering is the

315 dominant driver of community assembly (Cavender-Bares et al., 2009). Other work has found

316 evidence for abiotic stress leading to phylogenetic clustering of soil bacteria (Goberna et al.,

317 2014).

318

319 4.2. Bacterial communities in regenerating vs. primary forest

320 We found little evidence of differences in bacterial diversity and community composition

321 between regenerating and primary forest. Similar findings have been made in a similar system in

322 Borneo (Lee-Cruz et al., 2013; Tripathi et al., 2016, 2012). Network analysis, however, 
323 illuminated previously unnoticed differences in the structure of bacterial communities between

324 primary and regenerating forest. We proposed two, competing hypotheses for differences in

325 network structure: (H1) bacterial network structure would increase in complexity towards

326 primary vegetation; (H2) bacterial network structure would become less complex as fungal

327 networks became more complex under primary forest. We found that regenerating forest

328 networks were eight times more modular than primary forest networks, providing evidence that

329 the response of bacterial networks and fungal networks could be different, given that fungal

330 networks have been shown to increase in interaction strength with primary vegetation (Morriën

331 et al., 2017). Regenerating forest and oil palm networks were also significantly more modular

332 than random. Modularity measures the compartmentalization of a network into sub-networks, or

333 modules (Newman, 2006). A lower modularity value indicates that taxa within the network tend

334 to co-occur more with a wider range of other taxa. Ecologically, modularity has been interpreted

335 to indicate partitioning into groups of ecologically similar taxa and, thus, resistance of a network

336 to disturbance and loss of individual species (Burgos et al., 2007; Ding et al., 2015). Based on

337 this interpretation, high modularity in regenerating forest could indicate that these forests include

338 more ecological types than in primary forest.

339 We also found that all land-use types had lower transitivity than random. In some cases,

340 transitivity has been shown to be an indicator that network structure is dominated by keystone

341 species - species whose removal can have a disproportionate effect on overall community

342 structure (Berry and Widder, 2014). Our observed lower-than-random transitivity across all land-

343 use types suggests that bacterial community structure is not highly sensitive to loss of particular

344 taxonomic groupings. Because lower transitivity can be indicative of weaker interactions and

345 couplings within the bacterial community, non-transitive network structure has been inferred as 
346 indicative of co-existence (Narisawa et al., 2008). Our finding of lower-than-random transitivity

347 suggests fairly stable co-existence of bacterial types across land-use categories.

348 The taxa that played a key role in bacterial networks were also different between

349 regenerating and primary forests. In regenerating forests, the taxa with the most connections to

350 other taxa were Planctomycetes, GN02, Gemmatimonadetes, and Nitrospirae. By contrast, in

351 primary forest the most important taxa were NKB19, ZB3, Actinobacteria, and Elusimicrobia.

352 Thus, the network analysis highlights that land use can significantly alter the network structure

353 of the soil bacterial community, even if diversity indices do not show differences.

354 There are several important caveats to drawing ecological interpretations from network

355 topology. Because network structure shows a pattern, it is difficult to infer ecological process

356 based on assessment of the pattern alone (Bascompte, 2007). There are only a few examples of

357 systems in which it is well understood how network typology and form connects to function,

358 many of which tend to be at the cellular rather than ecological level (Ingolia, 2004; Price et al.,

359 2004). As more information becomes available on the ecological strategies of particular

360 microbial taxa — such as how they respond to abiotic conditions - making inference about

361 ecological dynamics from network structure will become more fruitful. Another limitation to co-

362 occurrence network analysis is that the nature of the interactions is vague. Much network

363 analysis in ecology focuses on well defined and quantified biotic interactions, such as food web

364 and mutualistic interactions (Ings et al., 2009). The nature of co-occurrence interactions could be

365 due to several factors, some being more ecologically meaningful than others. Methodologically,

366 network structure can be influenced by the method of network construction and null model

367 testing used (Connor et al., 2016; Weiss et al., 2016). 
369 potential ecological roles of understudied taxa. Because many microbial taxa are hard to culture,

370 network analysis may highlight the ecological strategies of organisms that are difficult to observe

371 directly. In our study, we observed that several of the taxa that play important network roles are

372 underdescribed ecologically. For instance, taxa that strongly positively co-occur with a well-

373 studied taxon may play similar ecological roles. This inference is supported by our finding that

374 the overall bacterial community is phylogenetically clustered, meaning that environmental

375 filtering is likely important to bacterial community structure. Co-occurring taxa, therefore,

376 should be co-occurring because they have similar environmental response strategies. However,

377 we observed that correlation in relative abundance only explains $19 \%$ of the variation in co-

378 occurrence, which suggests that similar response of taxa's relative abundances to environmental

379 conditions only explains a part of the nature of complex co-occurrence patterns.

381 4.3. Combining diversity, phylogenetic, and network analyses provides more insight

382 We found many rare taxa with high network centrality highlighting potentially important,

383 but understudied, microbial taxa that are overlooked by analyses of diversity or relative

384 abundance patterns. Specifically, taxa such as GN02, NKB19, ZB3, NC10, AD3, Parvarchaeota,

385 Armatimonadetes, and Fibrobacteres all played important roles in network centrality, but had

386 low relative abundances. Identifying understudied taxa has previously focused on identifying

387 taxa with high relative abundances in novel systems, such as surprisingly high relative

388 abundances of Verrucomicrobia in remnant patches of native prairie across the U.S. Midwest

389 (Fierer et al., 2013). Our approach suggests that rare taxa that are low in relative abundance also

390 warrant further research effort, as they may play an important role in bacterial communities and 
391 potentially connect to broader ecosystem functioning - this potential importance of rare taxa has

392 been shown for plant systems (Jain et al., 2014; Lyons and Schwartz, 2001) but not for

393 microscopic taxa that are far less well known but lend themselves well to network analysis due to

394 their high diversity.

$395 \quad$ Further integration of network approaches into microbial analyses requires understanding

396 how patterns between the two approaches overlap. For instance, it will be particularly important

397 to understand when and why relative abundances translate to network importance and when they

398 do not. In our analysis the relative abundance of Acidobacteria was lowest in oil palm soils, but

399 Acidobacteria had the greatest network centrality. Similarly, Actinobacteria relative abundance

400 was lowest in primary forest soils, but had the highest network centrality score. These patterns

401 between relative abundance and network centrality are seemingly idiosyncratic, so further

402 research into the drivers of network influence in the soil bacterial community is needed. This

403 work will likely require improved understanding of life history strategies of microbial taxa,

404 which overlaps with the research needs to develop understanding of microbial functional traits

405 (Aguilar-Trigueros et al., 2015; Thomas W. Crowther et al., 2014; Krause et al., 2014; Martiny et

406 al., 2015; Wallenstein and Hall, 2011; Wieder et al., 2014).

4084.4 Conclusion

409 Though soil fungal communities appear to be highly responsive to changes in vegetation

410 and carbon loss (McGuire et al., 2015), changes in bacterial communities under deforestation

411 may be principally driven by changes in environmental conditions associated with land-use

412 change. This implies that diversity changes in bacterial communities may be more ephemeral 
413 than changes to fungal communities, given that $\mathrm{pH}$ can change over shorter time periods than

414 soil carbon and dominant vegetation structure.

415 Understanding the nature of the change in these bacterial communities has largely

416 focused on shifts in relative abundances and diversity. Our finding that bacterial diversity

417 increases under oil palm aligns with previous findings, but we also shed new light on the nature

418 of bacterial community disassembly with land-use change. Network analysis highlights strong

419 differences in network structure between regenerating and primary forests that do not appear in

420 analyses of diversity or relative abundance patterns. Our analysis identified bacterial taxa that

421 play central roles in network structure, but have low relative abundances. These taxa warrant

422 further research effort to identify their functional roles in the ecosystem.

423 Our finding that the structure of bacterial networks differed between regenerating and

424 primary forests also suggests that microbial community analysis needs to go beyond assessment

425 of diversity and relative abundance patterns to unravel the nature of changes to bacterial

426 communities under land-use change. Analytic tools that go beyond diversity analyses are widely

427 applied in community ecology and our data suggests that greater application of these methods

428 could strongly benefit inference in microbial ecology.

430 Author Contributions

431 K.L.M., H.D., C.B., S.M.G, C.M.G, M.R.G, A.M, and N.Y designed the field sampling,

432 conducted field work, processed soils, and extracted DNA; B.L.T helped with study design; P.M

433 and F.Q.B helped with study design and field sampling; J.A.G amplified and sequenced DNA;

434 J.L and N.F processed sequence data; S.A.W analyzed data and wrote the first draft of the

435 manuscript; all authors provided feedback on the final version of the manuscript. 


\section{Acknowledgements}

438 Lee Su See, Stuart Davies, and the Center for Tropical Forest Science assisted with logistical

439 support for field work. Permits were granted by the Forestry Research Institute Malaysia, the

440 Economic Planning Unit of Malaysia, and the United States Department of Agriculture. Research

441 was supported by the National Science Foundation (NSF DEB 1120011 to K.L.M).

442

443 Conflict of Interest

444 The authors declare no conflict of interest.

445

\section{References}

447 Adzmi, Y., Suhaimi, W.C., Husni, M.S.A., Ghazali, H.M., Amir, S.K., Baillie, I., 2010.

448 Heterogeneity of Soil Morphology and Hydrology on the 50 Ha Long-Term Ecological

449 Research Plot At Pasoh, Peninsular Malaysia. Journal of Tropical Forest Science 22, 21$450 \quad 35$.

451 Aguilar-Trigueros, C.A., Hempel, S., Powell, J.R., Anderson, I.C., Antonovics, J., Bergmann, J., 452 Cavagnaro, T.R., Chen, B., Hart, M.M., Klironomos, J., Petermann, J.S., Verbruggen, E., 453 Veresoglou, S.D., Rillig, M.C., 2015. Branching out: Towards a trait-based understanding 454 of fungal ecology. Fungal Biology Reviews 29, 34-41. doi:10.1016/j.fbr.2015.03.001

455 Asner, G., Rudel, T., Aide, T., DeFries, R., Emerson, R., 2009. A Contemporary Assessment of

456 Change in Humid Tropical Forests. Conservation Biology 23, 1386-1395.

457 doi:10.1111/j.1523-1739.2009.01333.x

458 Bagchi, R., Swinfield, T., Gallery, R.E., Lewis, O.T., Gripenberg, S., Narayan, L., Freckleton, 
R.P., 2010. Testing the Janzen-Connell mechanism: pathogens cause overcompensating

460 density dependence in a tropical tree. Ecology Letters 13, 1262-1269. doi:10.1111/j.14610248.2010.01520.x

462 Barberán, A., McGuire, K.L., Wolf, J.A., Jones, F.A., Wright, S.J., Turner, B.L., Essene, A.,

463 Hubbell, S.P., Faircloth, B.C., Fierer, N., 2015. Relating belowground microbial

464 composition to the taxonomic, phylogenetic, and functional trait distributions of trees in a

465 tropical forest. Ecology Letters 18, 1397-1405. doi:10.1111/ele.12536

466 Barrat, A., Barthelemy, M., Pastor-Satorras, R., Vespignani, A., 2004. The architecture of

$467 \quad$ complex weighted networks. Proceedings of the National Academy of Sciences 101, 3747-

$468 \quad$ 3752. doi:10.1073/pnas.0400087101

469 Bascompte, J., 2007. Networks in ecology. Basic and Applied Ecology 8, 485-490.

$470 \quad$ doi:10.1016/j.baae.2007.06.003

471 Berry, D., Widder, S., 2014. Deciphering microbial interactions and detecting keystone species

472 with co-occurrence networks. Frontiers in Microbiology 5. doi:10.3389/fmicb.2014.00219

473 Blonder, B., Morueta-Holme, N., 2015. netassoc: Inference of Species Associations from Co-

$474 \quad$ Occurrence Data.

475 Brearley, F., 2015. Microbial Functioning in Response to a Simulated Drought in Malaysian

476 Rain Forest and Oil Palm Soils, in: Brearley, F., Thomas, A. (Eds.), Land-Use Change

477 Impacts on Soil Processes: Tropical and Savannah Ecosystems. CABI Publishing,

$478 \quad$ Oxfordshire, UK, pp. 31-40.

479 Brooks, T.M., Mittermeier, R.A., Mittermeier, C.G., da Fonseca, G.A.B., Rylands, A.B.,

480 Konstant, W.R., Flick, P., Pilgrim, J., Oldfield, S., Magin, G., Hilton-Taylor, C., 2002.

481 Habitat Loss and Extinction in the Hotspots of Biodiversity. Conservation Biology 16, 909- 
483 Burgos, E., Ceva, H., Perazzo, R.P.J., Devoto, M., Medan, D., Zimmermann, M., María Delbue, 484 A., 2007. Why nestedness in mutualistic networks? Journal of Theoretical Biology 249, 485 307-313. doi:10.1016/j.jtbi.2007.07.030

486 Caporaso, J.G., Lauber, C.L., Walters, W.A., Berg-Lyons, D., Huntley, J., Fierer, N., Owens, 487 S.M., Betley, J., Fraser, L., Bauer, M., Gormley, N., Gilbert, J.A., Smith, G., Knight, R., 488 2012. Ultra-high-throughput microbial community analysis on the Illumina HiSeq and 489 MiSeq platforms. The ISME Journal 6, 1621-4. doi:10.1038/ismej.2012.8

490 Carlson, K.M., Curran, L.M., Ratnasari, D., Pittman, A.M., Soares-Filho, B.S., Asner, G.P., 491 Trigg, S.N., Gaveau, D.A., Lawrence, D., Rodrigues, H.O., 2012. Committed carbon 492 emissions, deforestation, and community land conversion from oil palm plantation expansion in West Kalimantan, Indonesia. Proceedings of the National Academy of

494 Sciences of the United States of America 109, 7559-64. doi:10.1073/pnas.1200452109

495 Cavender-Bares, J., Kozak, K.H., Fine, P.V. a, Kembel, S.W., 2009. The merging of community 496 ecology and phylogenetic biology. Ecology Letters 12, 693-715. doi:10.1111/j.1461$497 \quad$ 0248.2009.01314.x

498 Connor, N., Barberán, A., Clauset, A., 2016. Using null models to infer microbial co-occurrence $499 \quad$ networks. doi:10.1101/070789

500 Core, R.T., 2016. R: A language and environment for statistical computing.

501 Crowther, T.W., Maynard, D.S., Crowther, T.R., Peccia, J., Smith, J.R., Bradford, M.A., 2014.

$502 \quad$ Untangling the fungal niche: the trait-based approach. Frontiers in Microbiology 5.

503 doi: $10.3389 /$ fmicb.2014.00579

504 Crowther, T.W., Maynard, D.S., Leff, J.W., Oldfield, E.E., McCulley, R.L., Fierer, N., Bradford, 

M.A., 2014. Predicting the responsiveness of soil biodiversity to deforestation: a crossbiome study. Global Change Biology 20, 2983-94. doi:10.1111/gcb.12565

507 Csardi, G., Nepusz, T., 2006. The igraph software package for complex network research.

508 InterJournal, Complex Systems 1695, 1-9.

509 D’Angelo, H., McGuire, K., Gillikin, C., Brearley, F., Merrer, D., 2015. Evaluating the Impact of

510 Oil Palm Agriculture and Logging on Soil Microbial Communites in South-east Asia, in:

511 Brearley, F., Thomas, A. (Eds.), Land-Use Change Impacts on Soil Processes: Tropical and

512 Savannah Ecosystems. CABI Publishing, Oxfordshire, UK, pp. 21-30.

513 da C Jesus, E., Marsh, T.L., Tiedje, J.M., de S Moreira, F.M., 2009. Changes in land use alter the 514 structure of bacterial communities in Western Amazon soils. The ISME Journal 3, 1004-11. $515 \quad$ doi:10.1038/ismej.2009.47

516 de Carvalho, T.S., da Conceição Jesus, E., Barlow, J., Gardner, T.A., Soares, I.C., Tiedje, J.M., 517 de Souza Moreira, F.M., 2016. Land use intensification in the humid tropics increased both 518 alpha and beta diversity of soil bacteria. Ecology. doi:10.1002/ecy.1513

519 Ding, J., Zhang, Y., Deng, Y., Cong, J., Lu, H., Sun, X., Yang, C., Yuan, T., Van Nostrand, J.D.,

520 Li, D., Zhou, J., Yang, Y., 2015. Integrated metagenomics and network analysis of soil 521 microbial community of the forest timberline. Scientific Reports 5, 7994.

522 doi: $10.1038 /$ srep07994

523 Dirzo, R., Raven, P.H., 2003. Global State of Biodiversity and Loss. Annual Review of

524 Environment and Resources 28, 137-167. doi:10.1146/annurev.energy.28.050302.105532

525 Edgar, R.C., 2013. UPARSE: highly accurate OTU sequences from microbial amplicon reads.

$526 \quad$ Nature Methods 10, 996-998. doi:10.1038/nmeth.2604

527 Falkowski, P.G., Fenchel, T., Delong, E.F., 2008. The microbial engines that drive Earth's 
biogeochemical cycles. Science 320, 1034-9. doi:10.1126/science.1153213

529 Fierer, N., Ladau, J., Clemente, J.C., Leff, J.W., Owens, S.M., Pollard, K.S., Knight, R., Gilbert,

530 J. a, McCulley, R.L., 2013. Reconstructing the microbial diversity and function of pre-

531 agricultural tallgrass prairie soils in the United States. Science (New York, N.Y.) 342, 621-

$532 \quad$ 4. doi: $10.1126 /$ science. 1243768

533 Fierer, N., Lauber, C.L., Ramirez, K.S., Zaneveld, J., Bradford, M.A., Knight, R., 2012.

534 Comparative metagenomic, phylogenetic and physiological analyses of soil microbial

535 communities across nitrogen gradients. The ISME Journal 6, 1007-1017.

536 doi:10.1038/ismej.2011.159

537 Fierer, N., Schimel, J.P., Holden, P.A., 2003. Variations in microbial community composition

538 through two soil depth profiles. Soil Biology and Biochemistry 35, 167-176.

539 doi:10.1016/S0038-0717(02)00251-1

540 Freeman, L.C., 1978. Centrality in social networks conceptual clarification. Social Networks 1,

$541 \quad 215-239$. doi:10.1016/0378-8733(78)90021-7

542 Gardner, T.A., Barlow, J., Chazdon, R., Ewers, R.M., Harvey, C.A., Peres, C.A., Sodhi, N.S.,

543 2009. Prospects for tropical forest biodiversity in a human-modified world. Ecology Letters

$544 \quad 12,561-582$. doi:10.1111/j.1461-0248.2009.01294.x

545 Goberna, M., Navarro-Cano, J.A., Valiente-Banuet, A., García, C., Verdú, M., 2014. Abiotic

546 stress tolerance and competition-related traits underlie phylogenetic clustering in soil

547 bacterial communities. Ecology Letters 17, 1191-1201. doi:10.1111/ele.12341

548 Hansen, M.C., Potapov, P. V., Moore, R., Hancher, M., Turubanova, S.A., Tyukavina, A., Thau,

549 D., Stehman, S. V., Goetz, S.J., Loveland, T.R., Kommareddy, A., Egorov, A., Chini, L.,

$550 \quad$ Justice, C.O., Townshend, J.R.G., 2013. High-Resolution Global Maps of 21st-Century 
552 Hol, W.H.G., de Boer, W., de Hollander, M., Kuramae, E.E., Meisner, A., van der Putten, W.H., 553 2015. Context dependency and saturating effects of loss of rare soil microbes on plant 554 productivity. Frontiers in Plant Science 6. doi:10.3389/fpls.2015.00485

555 Hol, W.H.G., de Boer, W., Termorshuizen, A.J., Meyer, K.M., Schneider, J.H.M., van Dam,

556 N.M., van Veen, J.A., van der Putten, W.H., 2010. Reduction of rare soil microbes modifies 557 plant-herbivore interactions. Ecology Letters 13, 292-301. doi:10.1111/j.1461$558 \quad 0248.2009 .01424 . x$

559 Hurlbert, S., Lombardi, C., 2009. Final collapse of the Neyman-Pearson decision theoretic 560 framework and rise of the neoFisherian. Annales Zoologici Fennici 46, 311-349.

561 Ingolia, N.T., 2004. Topology and Robustness in the Drosophila Segment Polarity Network.

$562 \quad$ PLoS Biology 2, e123. doi:10.1371/journal.pbio.0020123

563 Ings, T.C., Montoya, J.M., Bascompte, J., Blüthgen, N., Brown, L., Dormann, C.F., Edwards, F.,

564 Figueroa, D., Jacob, U., Jones, J.I., Lauridsen, R.B., Ledger, M.E., Lewis, H.M., Olesen, 565 J.M., van Veen, F.J.F., Warren, P.H., Woodward, G., 2009. Review: Ecological networks 566 beyond food webs. Journal of Animal Ecology 78, 253-269. doi:10.1111/j.1365$567 \quad 2656.2008 .01460 . x$

568 Jain, M., Flynn, D.F.B., Prager, C.M., Hart, G.M., Devan, C.M., Ahrestani, F.S., Palmer, M.I., 569 Bunker, D.E., Knops, J.M.H., Jouseau, C.F., Naeem, S., 2014. The importance of rare 570 species: A trait-based assessment of rare species contributions to functional diversity and 571 possible ecosystem function in tall-grass prairies. Ecology and Evolution 4, 104-112. 572 doi:10.1002/ece3.915

573 Kembel, S.W., Cowan, P.D., Helmus, M.R., Cornwell, W.K., Morlon, H., Ackerly, D.D., 
Blomberg, S.P., Webb, C.O., 2010. Picante: R tools for integrating phylogenies and

575 ecology. Bioinformatics 26, 1463-1464. doi:10.1093/bioinformatics/btq166

576 Kiers, E.T., Lovelock, C.E., Krueger, E.L., Herre, E.A., 2000. Differential effects of tropical

577 arbuscular mycorrhizal fungal inocula on root colonization and tree seedling growth:

578 implications for tropical forest diversity. Ecology Letters 3, 106-113. doi:10.1046/j.1461-

$579 \quad 0248.2000 .00126 . x$

580 Krause, S., Le Roux, X., Niklaus, P.A., Van Bodegom, P.M., Lennon, J.T., Bertilsson, S.,

581 Grossart, H.-P., Philippot, L., Bodelier, P.L.E., 2014. Trait-based approaches for

582 understanding microbial biodiversity and ecosystem functioning. Frontiers in Microbiology

583 5. doi: $10.3389 /$ fmicb.2014.00251

584 Lauber, C.L., Hamady, M., Knight, R., Fierer, N., 2009. Pyrosequencing-based assessment of

585 soil $\mathrm{pH}$ as a predictor of soil bacterial community structure at the continental scale. Applied

586 and Environmental Microbiology 75, 5111-20. doi:10.1128/AEM.00335-09

587 Lee-Cruz, L., Edwards, D.P., Tripathi, B.M., Adams, J.M., 2013. Impact of Logging and Forest

588 Conversion to Oil Palm Plantations on Soil Bacterial Communities in Borneo. Applied and

589 Environmental Microbiology 79, 7290-7297. doi:10.1128/AEM.02541-13

590 Leff, J.W., Jones, S.E., Prober, S.M., Barberán, A., Borer, E.T., Firn, J.L., Harpole, W.S.,

591 Hobbie, S.E., Hofmockel, K.S., Knops, J.M.H., McCulley, R.L., La Pierre, K., Risch, A.C.,

592 Seabloom, E.W., Schütz, M., Steenbock, C., Stevens, C.J., Fierer, N., 2015. Consistent

593 responses of soil microbial communities to elevated nutrient inputs in grasslands across the

594 globe. Proceedings of the National Academy of Sciences 201508382.

595 doi:10.1073/pnas. 1508382112

596 Locey, K.J., Lennon, J.T., 2016. Scaling laws predict global microbial diversity. Proceedings of 
the National Academy of Sciences 113, 5970-5975. doi:10.1073/pnas.1521291113

598 Lyons, K.G., Schwartz, M.W., 2001. Rare species loss alters ecosystem function - invasion 599 resistance. Ecology Letters 4, 358-365. doi:10.1046/j.1461-0248.2001.00235.x

600 Ma, B., Wang, H., Dsouza, M., Lou, J., He, Y., Dai, Z., Brookes, P.C., Xu, J., Gilbert, J.A., 601 2016. Geographic patterns of co-occurrence network topological features for soil microbiota 602 at continental scale in eastern China. The ISME Journal 10, 1891-1901. 603 doi:10.1038/ismej.2015.261

604 Mangan, S.A., Schnitzer, S.A., Herre, E.A., Mack, K.M.L., Valencia, M.C., Sanchez, E.I., Bever, 605 J.D., 2010. Negative plant-soil feedback predicts tree-species relative abundance in a 606 tropical forest. Nature 466, 752-755. doi:10.1038/nature09273

607 Manokaran, N., Seng, Q., Ashton, P., LaFrankie, J., Noor, N., Ahmad, W., Okuda, T., 2004.

608 Pasoh forest dynamics plot, peninsular Malaysia, in: Tropical Forest Diversity and 609 Dynamics: Findings from a Large-Scale Plot Network. pp. 585-598.

610 Martiny, J.B.H., Jones, S.E., Lennon, J.T., Martiny, A.C., 2015. Microbiomes in light of traits: A 611 phylogenetic perspective. Science 350, aac9323-aac9323. doi:10.1126/science.aac9323

612 McDonald, D., Price, M.N., Goodrich, J., Nawrocki, E.P., DeSantis, T.Z., Probst, A., Andersen, 613 G.L., Knight, R., Hugenholtz, P., 2012. An improved Greengenes taxonomy with explicit 614 ranks for ecological and evolutionary analyses of bacteria and archaea. The ISME Journal 6, 615 610-618. doi:10.1038/ismej.2011.139

616 McGuire, K.L., D’Angelo, H., Brearley, F.Q., Gedallovich, S.M., Babar, N., Yang, N., Gillikin, 617 C.M., Gradoville, R., Bateman, C., Turner, B.L., Mansor, P., Leff, J.W., Fierer, N., 2015. 618 Responses of Soil Fungi to Logging and Oil Palm Agriculture in Southeast Asian Tropical 619 Forests. Microbial Ecology 69, 733-747. doi:10.1007/s00248-014-0468-4 
620 Morriën, E., Hannula, S.E., Snoek, L.B., Helmsing, N.R., Zweers, H., de Hollander, M., Soto,

621 R.L., Bouffaud, M.-L., Buée, M., Dimmers, W., Duyts, H., Geisen, S., Girlanda, M.,

622 Griffiths, R.I., Jørgensen, H.-B., Jensen, J., Plassart, P., Redecker, D., Schmelz, R.M.,

623 Schmidt, O., Thomson, B.C., Tisserant, E., Uroz, S., Winding, A., Bailey, M.J., Bonkowski,

624 M., Faber, J.H., Martin, F., Lemanceau, P., de Boer, W., van Veen, J.A., van der Putten,

625 W.H., 2017. Soil networks become more connected and take up more carbon as nature

626 restoration progresses. Nature Communications 8, 14349. doi:10.1038/ncomms 14349

627 Murray, B.R., Thrall, P.H., Gill, A.M., Nicotra, A.B., 2002. How plant life-history and

628 ecological traits relate to species rarity and commonness at varying spatial scales. Austral

629 Ecology 27, 291-310. doi:10.1046/j.1442-9993.2002.01181.x

630 Narisawa, N., Haruta, S., Arai, H., Ishii, M., Igarashi, Y., 2008. Coexistence of Antibiotic-

631 Producing and Antibiotic-Sensitive Bacteria in Biofilms Is Mediated by Resistant Bacteria.

632 Applied and Environmental Microbiology 74, 3887-3894. doi:10.1128/AEM.02497-07

633 Newman, M.E.J., 2006. Modularity and community structure in networks. Proceedings of the

634 National Academy of Sciences 103, 8577-8582. doi:10.1073/pnas.0601602103

635 Newman, M.E.J., 2002. Assortative Mixing in Networks. Physical Review Letters 89, 208701.

636 doi:10.1103/PhysRevLett.89.208701

637 Oksanen, J., Blanchet, F.G., Friendly, M., Kindt, R., Legendre, P., McGlinn, D., Minchin, P.R.,

638 O’Hara, R.B., Simpson, G.L., Solymos, P., Stevens, M.H.H., Szoecs, E., Wagner, H.H.,

639 2016. vegan: Community Ecology Package.

640 Prescott, C.E., Grayston, S.J., 2013. Tree species influence on microbial communities in litter

641 and soil: Current knowledge and research needs. Forest Ecology and Management.

642 doi:10.1016/j.foreco.2013.02.034 
643 Price, N.D., Reed, J.L., Palsson, B.Ø., 2004. Genome-scale models of microbial cells: evaluating 644 the consequences of constraints. Nature Reviews Microbiology 2, 886-897. 645 doi:10.1038/nrmicro1023

646 Prober, S.M., Leff, J.W., Bates, S.T., Borer, E.T., Firn, J., Harpole, W.S., Lind, E.M., Seabloom, 647 E.W., Adler, P.B., Bakker, J.D., Cleland, E.E., DeCrappeo, N.M., DeLorenze, E., Hagenah, 648 N., Hautier, Y., Hofmockel, K.S., Kirkman, K.P., Knops, J.M.H., La Pierre, K.J., 649 MacDougall, A.S., McCulley, R.L., Mitchell, C.E., Risch, A.C., Schuetz, M., Stevens, C.J., 650 Williams, R.J., Fierer, N., 2015. Plant diversity predicts beta but not alpha diversity of soil 651 microbes across grasslands worldwide. Ecology Letters 18, 85-95. doi:10.1111/ele.12381

652 Ramirez, K.S., Craine, J.M., Fierer, N., 2012. Consistent effects of nitrogen amendments on soil 653 microbial communities and processes across biomes. Global Change Biology 18, 1918654 1927. doi:10.1111/j.1365-2486.2012.02639.x

655 Ramirez, K.S., Lauber, C.L., Knight, R., Bradford, M.A., Fierer, N., 2010. Consistent effects of 656 nitrogen fertilization on soil bacterial communities in contrasting systems. Ecology 91, $657 \quad 3463-70$.

658 Ramirez, K.S., Leff, J.W., Barbera, A., Bates, S.T., Betley, J., Crowther, T.W., Kelly, E.F., 659 Oldfield, E.E., Shaw, E.A., Steenbock, C., Bradford, M.A., Wall, D.H., Fierer, N., 2014. 660 Biogeographic patterns in below-ground diversity in New York City's Central Park are 661 similar to those observed globally. Proceedings of the Royal Society B.

662 Rodrigues, J.L.M., Pellizari, V.H., Mueller, R., Baek, K., Jesus, E.D.C., Paula, F.S., Mirza, B., 663 Hamaoui, G.S., Tsai, S.M., Feigl, B., Tiedje, J.M., Bohannan, B.J.M., Nüsslein, K., 2013. 664 Conversion of the Amazon rainforest to agriculture results in biotic homogenization of soil 665 bacterial communities. Proceedings of the National Academy of Sciences of the United 
States of America 110, 988-93. doi:10.1073/pnas.1220608110

667 Rousk, J., Bååth, E., Brookes, P.C., Lauber, C.L., Lozupone, C., Caporaso, J.G., Knight, R., 668 Fierer, N., 2010. Soil bacterial and fungal communities across a pH gradient in an arable 669 soil. The ISME Journal 4, 1340-51. doi:10.1038/ismej.2010.58

670 Shade, A., Jones, S.E., Caporaso, J.G., Handelsman, J., Knight, R., Fierer, N., Gilbert, J.A., 671 2014. Conditionally Rare Taxa Disproportionately Contribute to Temporal Changes in 672 Microbial Diversity. mBio 5, e01371-14-e01371-14. doi:10.1128/mBio.01371-14

673 Toberman, H., Freeman, C., Evans, C., Fenner, N., Artz, R.R.E., 2008. Summer drought

674 decreases soil fungal diversity and associated phenol oxidase activity in upland Calluna 675 heathland soil. FEMS Microbiology Ecology 66, 426-436. doi:10.1111/j.1574-

$676 \quad 6941.2008 .00560 . x$

677 Tripathi, B.M., Edwards, D.P., Mendes, L.W., Kim, M., Dong, K., Kim, H., Adams, J.M., 2016.

678 The impact of tropical forest logging and oil palm agriculture on the soil microbiome.

679 Molecular Ecology 25, 2244-2257. doi:10.1111/mec.13620

680 Tripathi, B.M., Kim, M., Lai-Hoe, A., Shukor, N.A.A., Rahim, R.A., Go, R., Adams, J.M., 2013. $681 \mathrm{pH}$ dominates variation in tropical soil archaeal diversity and community structure. FEMS $682 \quad$ Microbiology Ecology. doi:10.1111/1574-6941.12163

683 Tripathi, B.M., Kim, M., Singh, D., Lee-Cruz, L., Lai-Hoe, A., Ainuddin, a N., Go, R., Rahim, 684 R.A., Husni, M.H. a, Chun, J., Adams, J.M., 2012. Tropical Soil Bacterial Communities in 685 Malaysia: pH Dominates in the Equatorial Tropics Too. Microbial Ecology.

686 doi:10.1007/s00248-012-0028-8

687 Wallenstein, M.D., Hall, E.K., 2011. A trait-based framework for predicting when and where 688 microbial adaptation to climate change will affect ecosystem functioning. Biogeochemistry 
690 Wang, Q., Garrity, G.M., Tiedje, J.M., Cole, J.R., 2007. Naive Bayesian Classifier for Rapid 691 Assignment of rRNA Sequences into the New Bacterial Taxonomy. Applied and 692 Environmental Microbiology 73, 5261-5267. doi:10.1128/AEM.00062-07

693 Webb, C., Ackerly, D., 2002. Phylogenies and community ecology. Annual Review of Ecology $694 \quad \ldots 33,475-505$.

695 Webb, C.O., Ackerly, D.D., Kembel, S.W., 2008. Phylocom: software for the analysis of 696 phylogenetic community structure and trait evolution. Bioinformatics 24, 2098-2100. 697 doi:10.1093/bioinformatics/btn358

698 Weiss, S., Van Treuren, W., Lozupone, C., Faust, K., Friedman, J., Deng, Y., Xia, L.C., Xu, 699 Z.Z., Ursell, L., Alm, E.J., Birmingham, A., Cram, J.A., Fuhrman, J.A., Raes, J., Sun, F., 700 Zhou, J., Knight, R., 2016. Correlation detection strategies in microbial data sets vary 701 widely in sensitivity and precision. The ISME Journal 10, 1669-1681.

702 doi:10.1038/ismej.2015.235

703 Wieder, W.R., Grandy, a. S., Kallenbach, C.M., Bonan, G.B., 2014. Integrating microbial 704 physiology and physiochemical principles in soils with the MIcrobial-MIneral Carbon 705 Stabilization (MIMICS) model. Biogeosciences Discussions 11, 1147-1185.

706 doi:10.5194/bgd-11-1147-2014

707 Wood, S.A., Bradford, M.A., Gilbert, J.A., McGuire, K.L., Palm, C.A., Tully, K.L., Zhou, J., 708 Naeem, S., 2015. Agricultural intensification and the functional capacity of soil microbes on 709 smallholder African farms. Journal of Applied Ecology 52, 744-752. doi:10.1111/1365-

$710 \quad 2664.12416$


712 


\section{$713 \quad$ Figure Headings}

714 Figure 1. NMDS plot of soil bacterial communities under primary rainforest, regenerating

715 rainforest, and oil palm plantation in peninsular Malaysia.

716 Figure 2. Bar plot of relative abundances of bacterial taxa among the three land-use categories.

717 Taxa were included for which there was significant differences in relative abundances among at

718 least two of the categories. For visualization, plots are broken up by taxa with high relative

719 abundances (a) and low relative abundances (b).

720 Figure 3. Association network maps of soil bacterial communities under the three land-use

721 categories: regenerating forest (a), oil palm (b), and primary forest (c). The size of vertices is

722 proportional to the number of edges connecting each vertex.

723 Figure 4. Heat map of significant $(\mathrm{p}<0.05)$ co-occurrence values among individual taxa under

724 the three land-use categories: regenerating forest (a), oil palm (b), and primary forest (c). Red

725 indicates negative co-occurrence scores and blue indicates positive co-occurrence scores.

726 Correlation of species taxonomic relative abundances is a significant explanatory variable of co-

727 occurrence scores, but only explains a small portion of the overall variation (d). 
